\title{
Thermal and Efficiency Analysis of Five-level Multi-Level Clamped Multilevel Converter Considering Grid Codes
}

\author{
K. $\mathrm{Ma}^{2}$, R. S. Muñoz-Aguilar ${ }^{1}$, P. Rodríguez ${ }^{1}$, F. Blaabjerg ${ }^{2}$ \\ ${ }^{1}$ Department of Electrical Engineering, Technical University of Catalonia, \\ 08222 Terrassa-Barcelona, Spain \\ raul.munoz-aguilar@upc.edu,prodriguez@ee.upc.edu \\ ${ }^{2}$ Department of Energy Technology, Aalborg University, \\ Pontoppidanstraede 101, DK-9220 Aalborg East, Denmark \\ kema@et.aau.dk, fbl@et.aau.dk
}

\begin{abstract}
In this paper a five-level Multi-Clamped Multilevel Converter (5L-MLC ${ }^{2}$ ) topology is analyzed based on a typical grid integration application for renewable energy system. The loss and thermal distribution of the power devices in different switching legs are investigated and illustrated under rated condition. Afterwards, a loss and efficiency evaluation method is proposed and applied which take into account various injected reactive power ranges regulated by the grid codes. It is concluded that the loss and thermal distribution of $5 \mathrm{~L}-\mathrm{MLC}^{2}$ multilevel topology is unequal between the clamping switching legs and the main switching legs, it also shows a good and consistent efficiency characteristic under different output power ranges when complying with the grid codes.
\end{abstract}

Index Terms - DC-AC power conversion, multilevel converters, power electronics.

\section{INTRODUCTION}

The growing interests in the applications of high power and medium voltage power conversion continuously push the development of multilevel topologies to achieve not only more voltage levels but also more cost-effective topologies [1]. As wind turbines are now entering multi-MW power range, the multilevel converters with high cost-effective performance are becoming preferred [2].

In the last few decades, there are many multilevel converter topologies reported which have been generally classified into three groups: the Diode-Clamped Multi-Level converter (DCML), the Flying Capacitor Multi-Level converter (FCML), and the Cascade H-Bridge Multi-Level converter (CHBML) [1], [3]-[5]. In all of these modalities, there has been continuous development for better performance and reduced cost, which generally imply higher number of output voltage levels, reduced parts count and simple circuit structure. However, the attempts to increase the number of voltage levels have always resulted in large and bulky converter solutions or design complexities. It has been well known that a large number of clamping diodes and power switches are required for improving the output voltage quality of the DCML converter. In the case of the FCML topology, such desired performance is achieved with an increased number of capacitors with different VoltAmpere specifications, besides some specific control complexities due to their charging procedures. Equivalently, for the CHBML case, $N$ independent DC voltage sources must be provided for synthesizing $2 N+1$ output voltage levels, which also depends on the number of output phases [6].

Among the numerous multilevel topologies published over the past two decades, the three-level (3L) DCML converter, or the so-called Neutral-Point-Clamped (NPC) converter has been the most favorable approach of power electronics for Medium Voltage (MV) high power applications on the market [7]. Due to advancements in High-Voltage Insulated Gate Bipolar Transistors (HV-IGBT), the NPC technology has achieved good performances in modularity and robustness, which led to standardized industrial products. Some efforts for improving the NPC technology, by having its parts reduced, have been reported in the literature [8], [9].

Recently, a new series of Diode-Clamped based multilevel topologies called Multi-Level Clamped Multi-Level Converter $\left(\mathrm{MLC}^{2}\right)$ are proposed in [10]-[12], which introduces additional switching $\operatorname{leg}(\mathrm{s})$ to generate multilevel neutral point potential for the main switching legs. Thereby it creates an efficient way to extend the output voltage levels of the converter topology. Compared with the classical NPC counterparts with the same output voltage levels, the MLC ${ }^{2}$ topology can be accomplished by employing classical threelevel Neutral-Point-Clamped (NPC) building blocks. Thus, the overall circuit structure and modularity can be improved with reduced number of parts count. More detail analysis about these benefits can be found in [10].

In this paper, the performance of a five-level MLC topology in wind power application is evaluated. The focus will be on the thermal loading of power devices and efficiency when complying with the grid requirements. First, the loss and thermal behaviour of the MLC ${ }^{2}$ topology is investigated under rated condition, and then the operations with maximum allowable reactive power which is regulated by the grid codes, are simulated at different active power outputs. Finally, some experimental results are provided to validate the analysis. 


\section{CHARACTERISTICS OF MULTI-LEVEL CLAMPED MULTILEVEL CONVERTER (MLC ${ }^{2}$ )}

The family of multilevel converter topologies called Multi-level Clamped Multilevel Converter are proposed in [10]-[12], which introduce a multilevel clamping leg generating the multi-level neutral point potential for the main switching legs, and thereby a new way to extend the output voltage levels of the converter was created.

A 2 MW five-level $\mathrm{MLC}^{2}$ inverter (5L-MLC ${ }^{2}$ ) is chosen as a case study in this paper, whose topology is shown in Fig. 1, it introduces the same switching legs as the wellknown three level Neutral-Point-Clamp (3L-NPC) converter for both clamping leg and the main switching legs. The DC bus in this topology is split into four equal sections $\left(V_{2} V_{l}, V_{\text {. }}\right.$ $\left.{ }_{1}, V_{-2}\right)$, and the voltage stresses for the switches in the main phase legs (e.g. $\mathrm{S}_{\mathrm{m} 1}-\mathrm{S}_{\mathrm{m} 4}$ ) are $3 / 2$ times of that for the switches in the clamping leg (e.g. $\left.\mathrm{S}_{\mathrm{c} 1}-\mathrm{S}_{\mathrm{c} 4}\right)$ [10]-[12]. The basic converter parameters are summarized in Table I, which

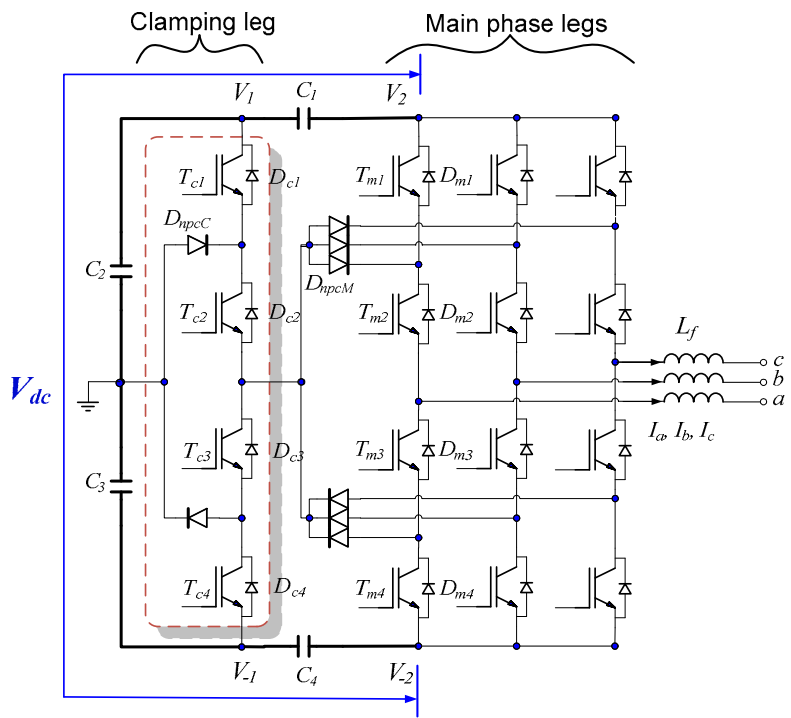

Fig. 1. Topology of 5L-MLC ${ }^{2}$ Converter (T means IGBT and D means frewheeling diode, while $\mathrm{S}$ means a switch which is composed of $\mathrm{T}$ and $\mathrm{D})$.

Table I. Rated parameters for $5 \mathrm{~L}-\mathrm{MLC}^{2}$ grid connected inverter.

\begin{tabular}{|l|c|}
\hline Rated output active power $P_{o}$ & $2 \mathrm{MW}$ \\
\hline DC bus voltage $V_{d c}$ & $4.8 \mathrm{kV} \mathrm{DC}$ \\
\hline Rated line-to-line grid voltage $V_{g}$ & $3 \mathrm{kV} \mathrm{rms}$ \\
\hline Fundamental frequency $f_{o}$ & $50 \mathrm{~Hz}$ \\
\hline Rated phase current $I_{\text {phase }}$ & $427 \mathrm{~A} \mathrm{rms}$ \\
\hline Carrier frequency $f_{c}$ & $1650 \mathrm{~Hz}$ \\
\hline Filter inductance $L_{f}$ & $2.15 \mathrm{mH}(0.15$ p.u. $)$ \\
\hline Power factor $P F$ & 1 \\
\hline
\end{tabular}

is based on a typical grid-connected medium-voltage converter application for wind turbine system.

After the parameters for converter are settled, the operating statuses can be simulated based on the Blockset PLECS in Simulink [13]. A Discontinuous Virtual Space Vector Modulation method, which was described in [12], is used in this paper. As indicated in Fig. 2 (a), the special modulation method eliminates some switching processes around the time of the maximum phase voltage, and threelevel voltage output is introduced during some period. As shown in Fig. 2 (b), the $5 \mathrm{~L}-\mathrm{MLC}^{2}$ converter can achieve five-level phase voltage and nine-level line-to-line voltage outputs, thereby achieve a high output voltage quality.

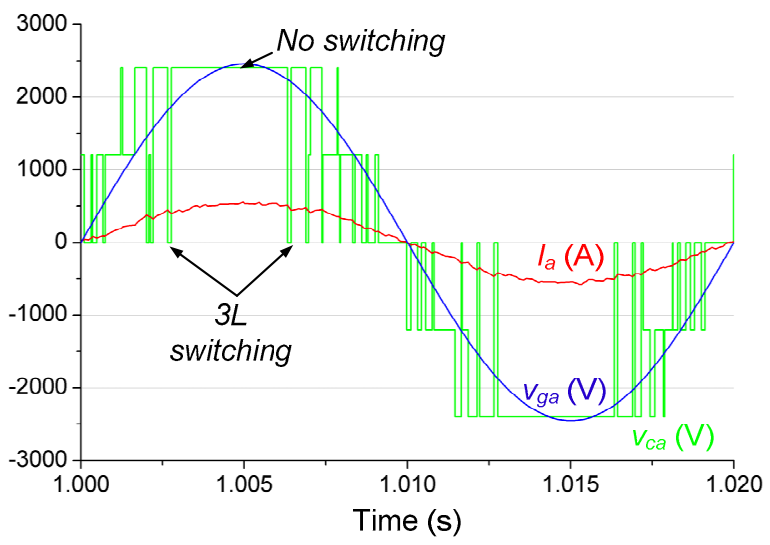

(a) Voltage and current output in one phase.

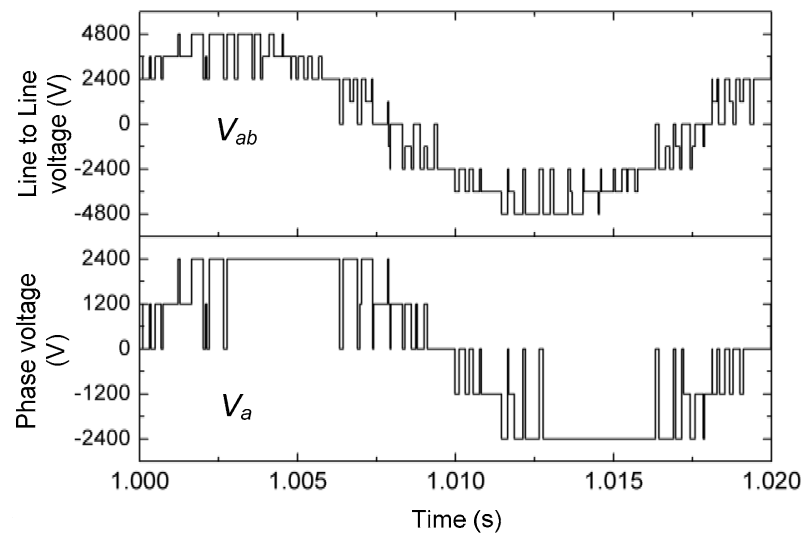

(b) Line to line voltage $\left(V_{a b}\right)$ and phase voltage $\left(V_{a}\right)$.

Fig. 2. Simulation outputs of $5 \mathrm{~L}-\mathrm{MLC}^{2}$ inverter at the given rated conditions in Table I.

\section{LOSS AND THERMAL ANALYSIS UNDER RATED CONDITION}

In order to conduct the loss and thermal analysis, the IGBT from Infineon FZ750R65KE3T (6500V/750A) is selected for the switches in the main phase legs $\mathrm{S}_{\mathrm{m} 1}-\mathrm{S}_{\mathrm{m} 4}$, and the IGBT FZ1000R33HL3 (3300V/1000A) are chosen for the switches in the clamping leg $\mathrm{S}_{\mathrm{c} 1}-\mathrm{S}_{\mathrm{c} 4}$. The rated current 
distributions within the main phase leg and clamping leg are shown in Fig. 3 (a) and Fig. 3 (b) respectively. It can be seen that the current distribution pattern of switching devices in both types of switching legs are quite different: the outer switches and clamping diodes in both types of the switching legs chop the load current more frequently than the inner switches. It is noted that the cycling frequency of the load current in the clamping leg $(150 \mathrm{~Hz})$ of Fig. 3 (b) is three times of that in the main phase leg $(50 \mathrm{~Hz})$ of Fig. 3 (a).

The loss distribution in the main phase leg and clamping leg are shown in Fig. 4. The detailed loss model is consistent with the one in [13]-[16]. It can be seen that the trends of loss distribution in this two types of converter legs are similar: the outer switches $\mathrm{S}_{\mathrm{m} 1} / \mathrm{S}_{\mathrm{c} 1}$ and clamping diodes $\mathrm{D}_{\mathrm{npcM}} / \mathrm{D}_{\mathrm{npcC}}$ have higher losses, and the switching loss is dominant compared to the conduction loss in the most stressed devices $\left(\mathrm{S}_{1}, \mathrm{~S}_{4}, \mathrm{D}_{\mathrm{npc}}\right)$.

Based on the loss information, the junction temperature of each switching device in the converter can be estimated. The used thermal models for a single switch and clamping diode

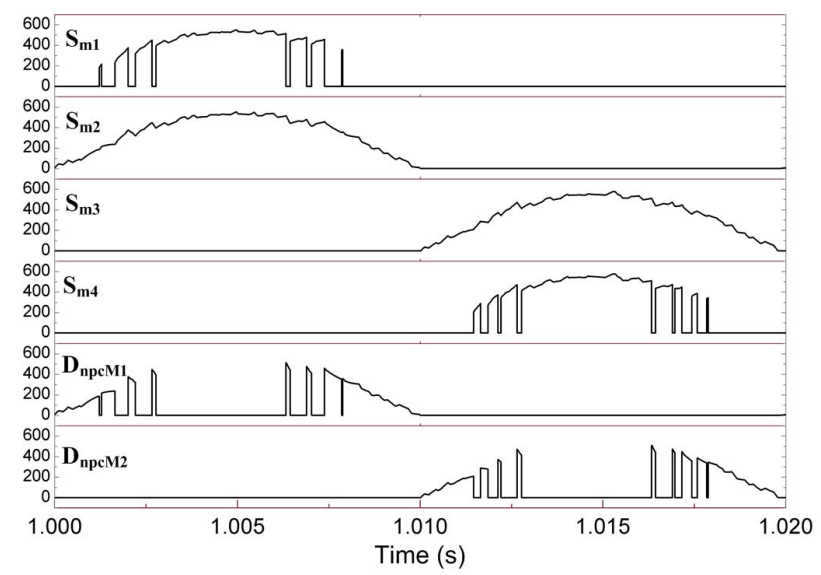

(a) Main phase leg

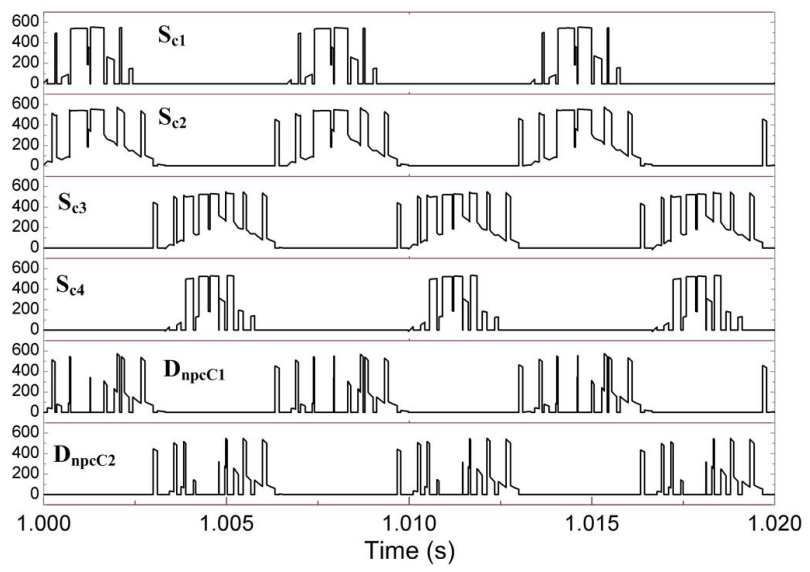

(b) Clamping leg

Fig. 3. Current distribution of $5 \mathrm{~L}-\mathrm{MLC}^{2}$ inverter in the main phase leg and the clamping leg $\left(V_{l l}=3 \mathrm{kVrms}, P_{o}=2 \mathrm{MW}, f_{s}=1.65 \mathrm{kHz}\right)$.

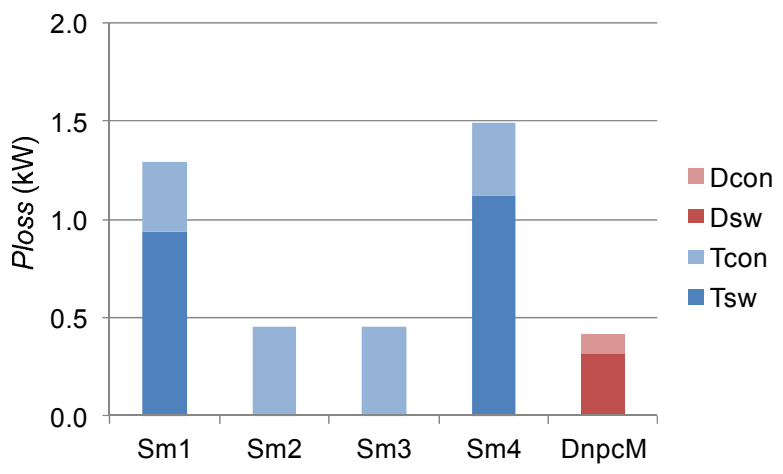

(a) Main phase leg

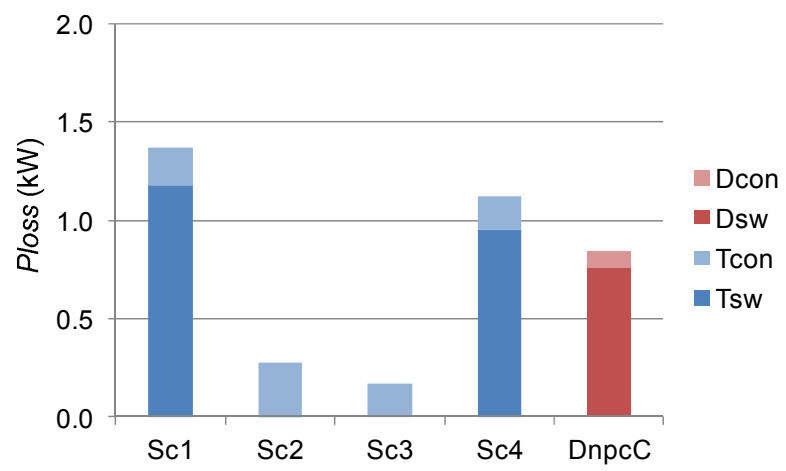

(b) Clamping leg

Fig. 4. Loss distribution of $5 \mathrm{~L}-\mathrm{MLC}^{2}$ inverter in the main phase leg and the clamping leg $\left(V_{l l}=3 \mathrm{kVrms}, P_{o}=2 \mathrm{MW}, f_{s}=1.65 \mathrm{kHz}\right)$.

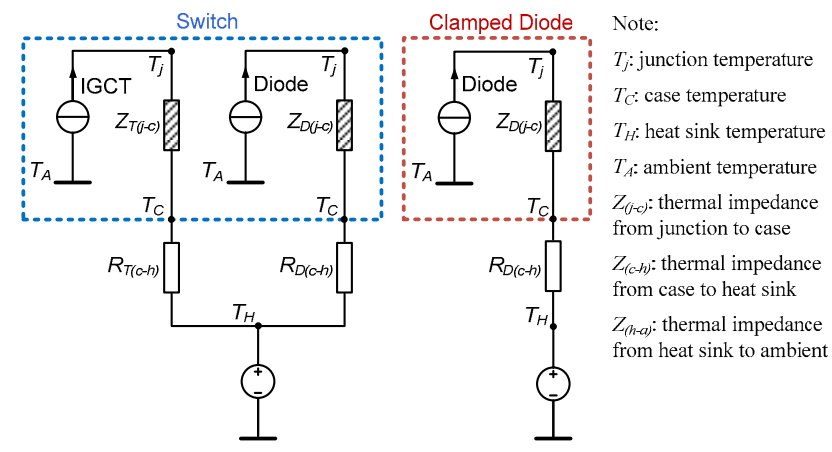

Fig. 5. Thermal models for the used power devices.

are indicated in Fig. 5 [13]-[15], [17] in which the thermal impedance from junction to case $Z_{T / D(j-c)}$ is modeled as a multi-layer Foster RC network. Each of the thermal parameters can be found from the manufacturer datasheets, but the manufacturer can only provide parameters inside IGBT modules. In order to establish the complete thermal model considering impedance from case to the ambient, $Z_{T / D(j-c)}$ has to be transferred to the equivalent Cauer RC network to facilitate the extension of thermal impedance outside IGBT module [13]. The heat sink temperature $T_{H}$ is typically much lower and more stable than the junction temperature $T_{j}$, therefore the $T_{H}$ in this paper is considered as 
a constant reference. It is noted that the $T_{H}$ is normally designed at $40{ }^{\circ} \mathrm{C}$ for the IGBT modules [18], for analysis considering the worst case, $T_{H}$ is assumed to be $50^{\circ} \mathrm{C}$ in this

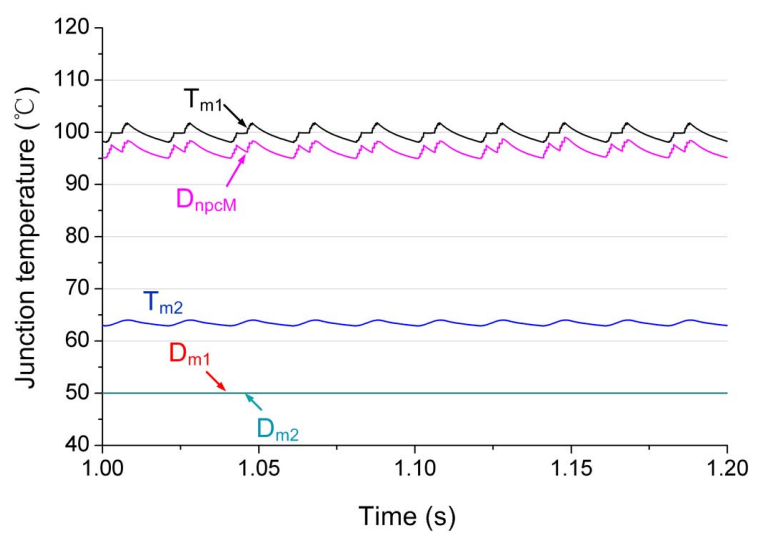

(a) Main leg

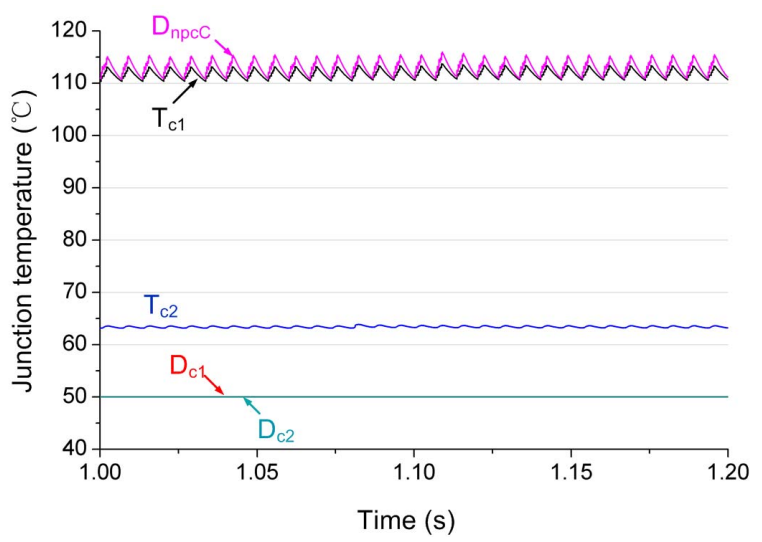

(b) Clamping leg

Fig. 6. Junction temperature distribution of $5 \mathrm{~L}-\mathrm{MLC}^{2}$ inverter in main phase leg and clamping leg (rated conditions specified in Table I).

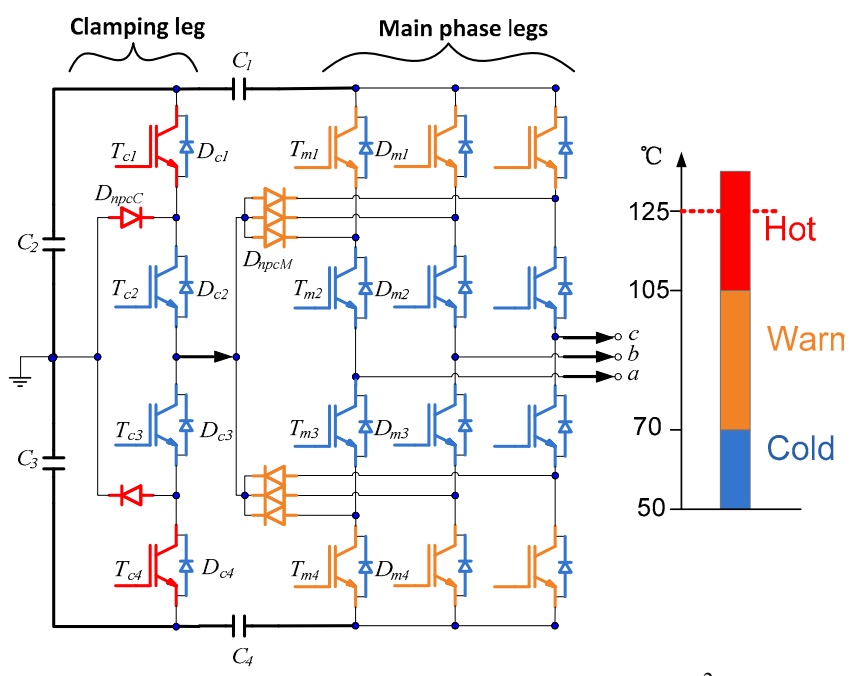

Fig. 7. Device thermal loading overview of $5 \mathrm{~L}-\mathrm{MLC}^{2}$ inverter (rated conditions in Table I). paper. However, the heat sink temperature may strongly depend on the operation site and the design of the heat sink system.

The thermal cycling of switching devices both in the main phase leg and clamping leg are shown in Fig. 6 (a) and Fig. 6 (b) respectively. It is obvious that the outer switch $T_{\mathrm{m} 1} / \mathrm{T}_{\mathrm{cl}}$ and clamping diode $\mathrm{D}_{\mathrm{npcM}} / \mathrm{D}_{\mathrm{npcC}}$ are the most stressed devices in the two types of switching legs. It is also noted that, because of larger thermal resistance, the mean junction temperature $T_{j m}$ in the switches of clamping leg (Fig. 6 (b)) is larger than the switches of main phase leg (Fig. 6 (a)), however, the junction temperature fluctuations $\Delta T_{j}$ in the switches of clamping leg are smaller because of three times cycling frequency $(150 \mathrm{~Hz})$. The smaller $\Delta T_{j}$ may benefit on the reliability performance of power devices referring to the life time models for power semiconductors [19]-[21].

According to the junction temperature distribution of the switches in Fig. 6, the power devices can be categorized into three types: the "hot" devices which have average junction temperatures $T_{j}$ above $105^{\circ} \mathrm{C}$, the "warm" devices which have $T_{j}$ between $70^{\circ} \mathrm{C}$ and $105^{\circ} \mathrm{C}$, and "cold" devices which have $T_{j}$ below $70^{\circ} \mathrm{C}$. The proportion of certain type of power devices will indicate the device utilization and loading information of a converter. The distributions of the three types of power devices at rated operating condition in the $5 \mathrm{~L}-\mathrm{MLC}^{2}$ inverter are shown in Fig. 7. The red color components represent the "hot" devices, yellow ones represent the "warm" devices and blue ones represent the "cold" devices. The "weak point" of the converter topology under the given modulation and rated condition can easily be located [22]. It is noted that in the same module, the chips of IGBTs and Diodes are separately soldered on the substrate, and thereby the paths of heat propagation for the chips of IGBT and diodes are different [17], [18]. As a results, the junction temperature on the chips of IGBT and freewheeling diodes are different even they are packaged in the same case.

The voltage and current stress imposed to the most stressed devices and the corresponding switching loss are shown in Fig. 8, in which the outer switch $\mathrm{T}_{\mathrm{m} 1}$ in the main phase leg and clamping diode $\mathrm{D}_{\mathrm{npcC}}$ in the clamping leg are illustrated. It is found that the switching loss in the main phase leg comes from the high voltage stress commutation (half DC bus voltage), while the switching loss in the clamping leg comes from the high frequency switching within one fundamental cycle. Thereby, the possible way to improve the efficiency of the $5 \mathrm{~L}-\mathrm{MLC}^{2}$ inverter is identified.

\section{LOSS AND EFFICIENCY ANALYSIS CONSIDERING REACTIVE POWER REGULATIONS BY GRID CODES}

One of the promising applications for the 5L-MLC ${ }^{2}$ topology is in the renewable energy generation, where the grid codes have strict regulations on the injected active/reactive power by the grid-connected converters. In this paper the operational power range required by German grid codes is chosen as an example [23], [24]. As shown in 


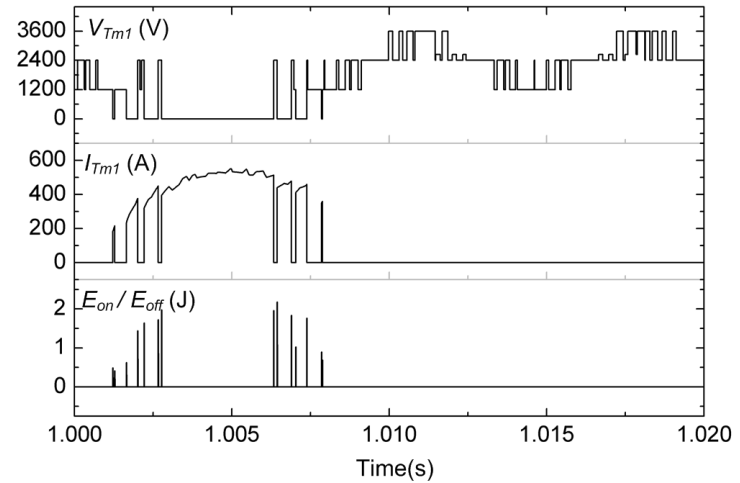

(a) $\mathrm{T}_{\mathrm{m} 1}$ in main phase leg.

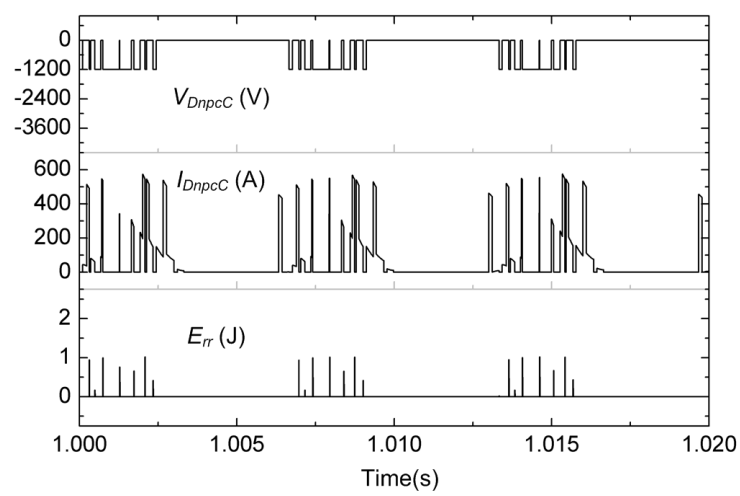

(b) $\mathrm{D}_{\mathrm{npcC} 1}$ in clamping leg.

Fig. 8. Voltage-Current-Switching loss energy waveforms of the most stressed devices $\left(E_{\text {on }} / E_{\text {off }}\right.$ is the switching on/off energy loss of IGBT, Err is the reverse recovery energy loss of diode).

Fig. 9, where three extreme operating conditions for the converter with maximum underexcited reactive power $Q_{\text {-max }}$ (reactive power $Q=-0.23$ p.u. if the active power $P>0.2$ p.u.), no reactive power $Q_{0}(Q=0$ p.u. $)$, and maximum overexcited reactive power $Q_{+\max }(Q=0.48$ p.u. if $P>0.2$ p.u. $)$ are chosen for the loss and efficiency analysis.

The power factor PF which are related to the delivered active power by the inverter is shown in Fig. 10, in which three extreme reactive power conditions are indicated. For the overexcited reactive power operating boundary $\mathrm{Q}_{\text {-max }}$, the power factor is between 0.4-0.9 lagging, while for the underexcited reactive power operating boundary, the power factor is between 0.65-0.95 leading. The changing power factors at different active powers of converter may largely modify the loss distribution of the power devices and the efficiency performance of the converter [25].

The loss distribution of the power devices in the main phase leg under the three extreme reactive power conditions when the output active power $P$ is at 1 p.u. and 0.5 p.u. are illustrated in Fig. 11 (a) and Fig. 11 (b) respectively. It can be seen that the loss distributions of power devices under

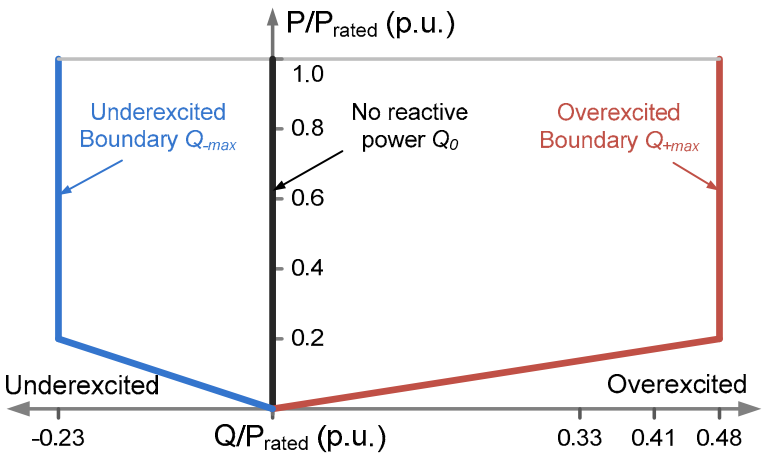

Fig. 9. German grid codes for $\mathrm{P} / \mathrm{Q}$ range of wind power inverter.

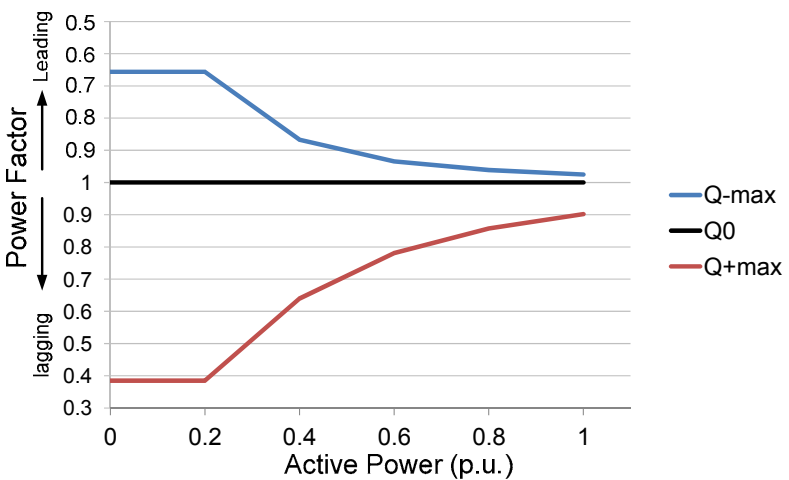

Fig. 10. Power factor vs. active power under different power operation boundaries given by Fig. 9

various active power and reactive power conditions are significantly different.

The efficiency performances of the $5 \mathrm{~L}-\mathrm{MLC}^{2}$ inverter at different active power outputs are shown in Fig. 12, in which the three extreme reactive power operation conditions are indicated. It can be seen that the converter shows a good and consistent efficiency characteristic under different output active powers under $\mathrm{Q}_{0}$ and $\mathrm{Q}$ - operation. Regarding to the overexcited reactive power boundary operation $\mathrm{Q}+$, it shows higher efficiency than Q- operation when the active power $\mathrm{P}$ $>0.6$ p.u., but significant lower efficiency when $\mathrm{P}<0.6$ p.u..

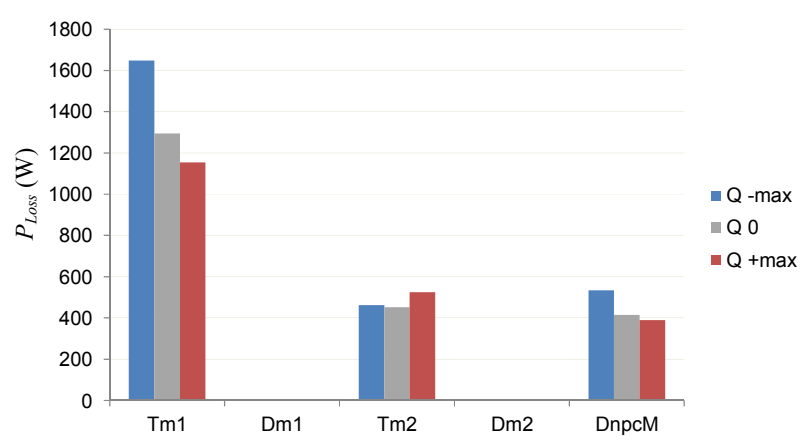

(a) $P=1$ p.u. 


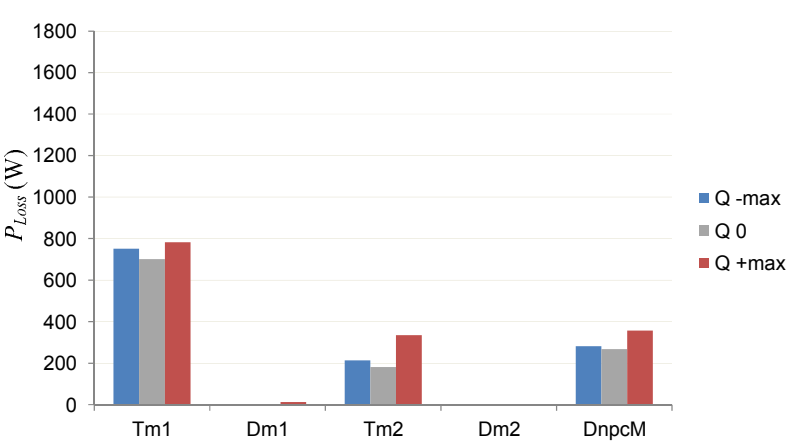

(a) $P=0.5$ p.u.,

Fig. 11. Loss distribution in the main switch leg under different reactive power boundaries (For $\mathrm{Q}_{0}$ operation $Q=0$ p.u., for $\mathrm{Q}_{+\max }$ operation $Q=0.48$ p.u., for $\mathrm{Q}_{\text {-max }}$ operation $Q=-0.23$ p.u. $V_{l l}=3$ $\left.\mathrm{kVrms}, P_{\text {rated }}=2 \mathrm{MW}, f_{s}=1.65 \mathrm{kHz}\right)$.

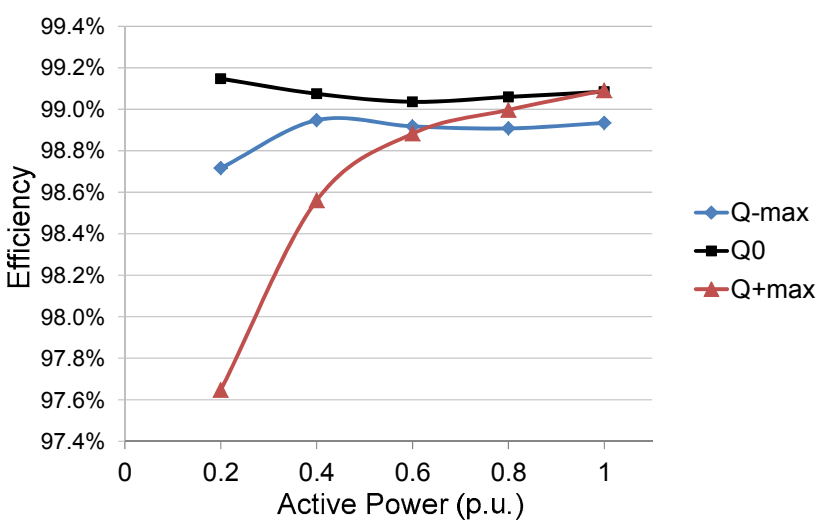

Fig. 12. Efficiency of 5L-MLC2 inverter at different reactive power operations ( $V_{l l}=3 \mathrm{kVrms}, P_{\text {rated }}=2 \mathrm{MW}, f_{s}=1.65 \mathrm{kHz}$ ).

\section{EXPERIMENTAL RESULTS}

The 5L-MLC ${ }^{2}$ was also tested experimentally. It has been built with Intelligent Power Modules from Mitsubishi (PM75DSA120) and ultrafast rectifier diodes (STTH120L0TV1).

The modulation strategy has been programmed in $\mathrm{C}$ code by using a $1006 \mathrm{dSpace}$ system. The control signals are connected to the IGBT modules by means of optic fibers. The IPM driver has also an isolation system and has been designed with a protection system against overcurrents, overvoltages and over-temperatures. In Fig. 13 the 5L-MLC ${ }^{2}$ power converter setup is shown.

The experiments were performed with a DC bus formed from regulated dc-voltage sources. The first experiment consists of characterizing the IPM by using the double pulse

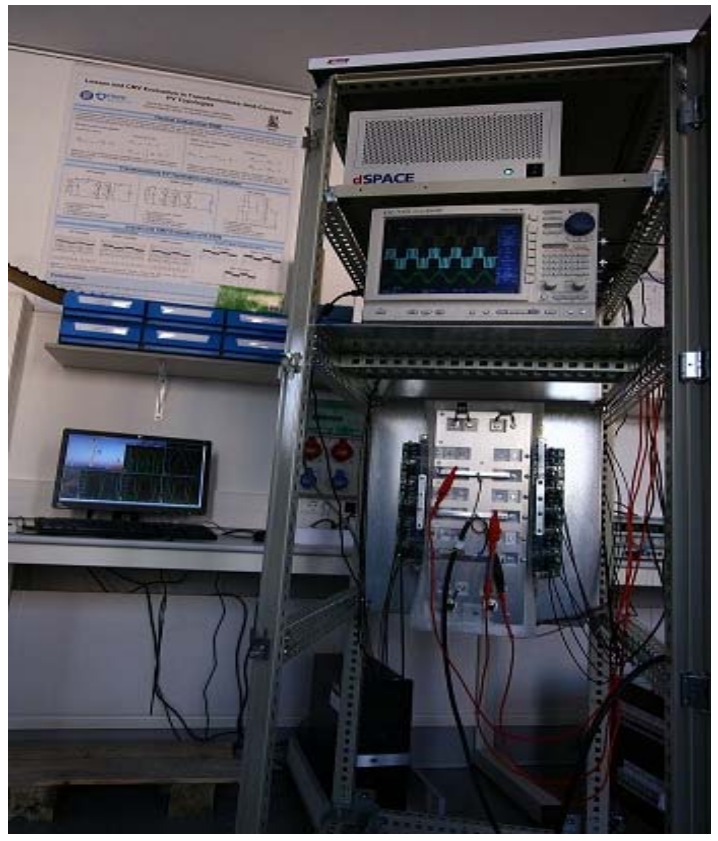

Fig. 13. Experimental setup of the $5 \mathrm{~L}-\mathrm{MLC}^{2}$ converter.
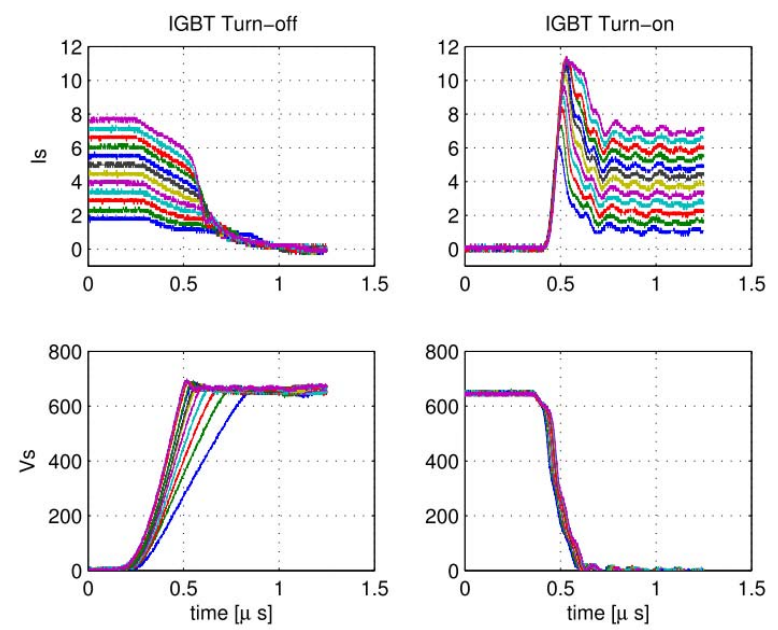

Fig. 14. IGBT switching waveforms for different collector currents

test using a $650 \mathrm{~V}$ single source. The second test is the modulation test for evaluating the losses of the whole converter. In this test four independent DC voltage sources connected in series were used, each of them has been set to $162.5 \mathrm{~V}$.

As aforementioned, in the first experiment, the IPM is characterized by using a double pulse testing [26] with the methodology introduced in [27], the results of these tests are depicted in Fig. 14 - Fig.19. In the test bench a $15 \mathrm{mH}$ inductor is used as load. Also, an $110 \mu \mathrm{F}$ capacitor is used to compensate the wire inductance. 

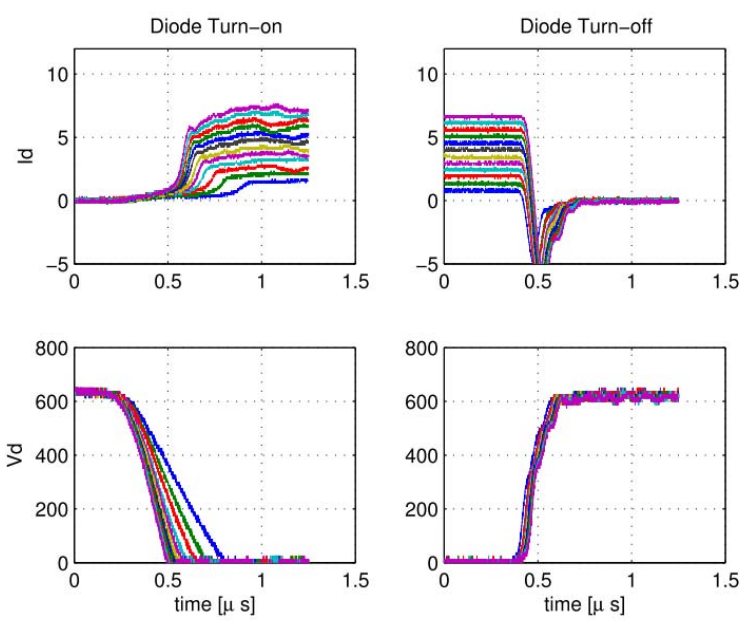

Fig. 15. Diode switching waveforms for different diode currents.
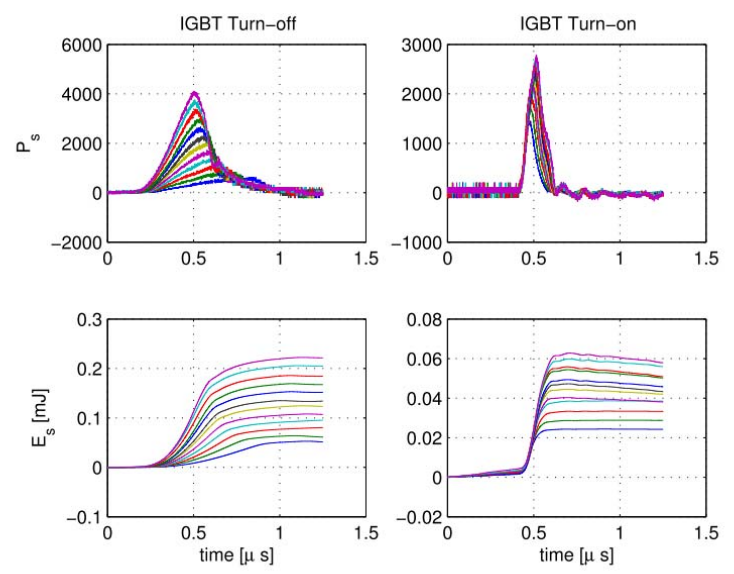

Fig. 16. IGBT power and energy losses for different collector currents.
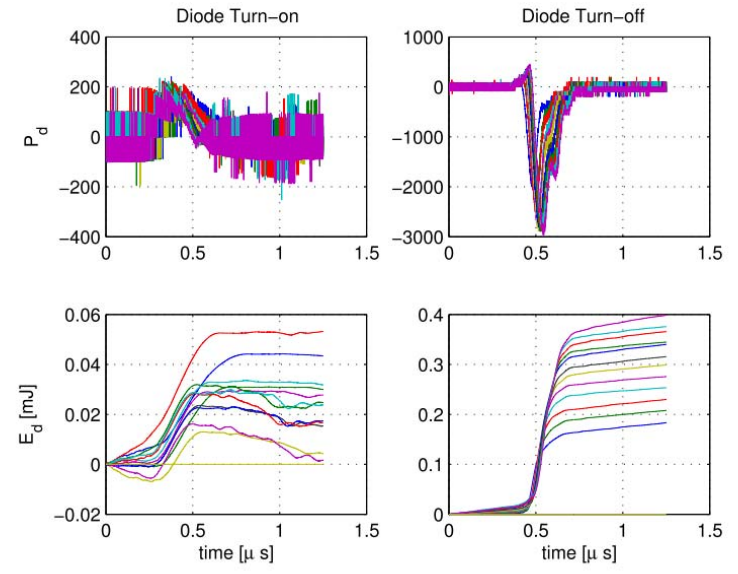

Fig. 17. Diode power and energy losses for different diode currents.

Fig. 14 and Fig. 15 present the turn-on and turn-off diode and IGBT waveforms for several collector currents. By using Matlab the power and energy losses were
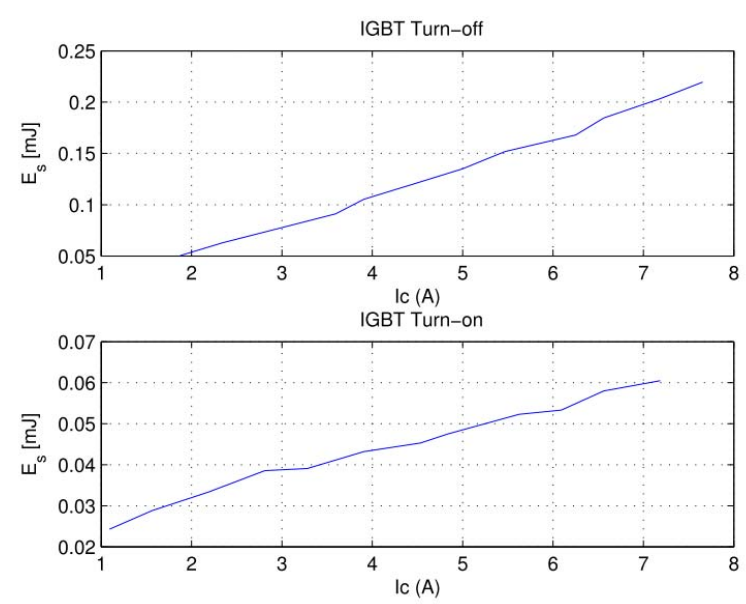

Fig. 18. IGBT energy losses as a function of the collector currents.

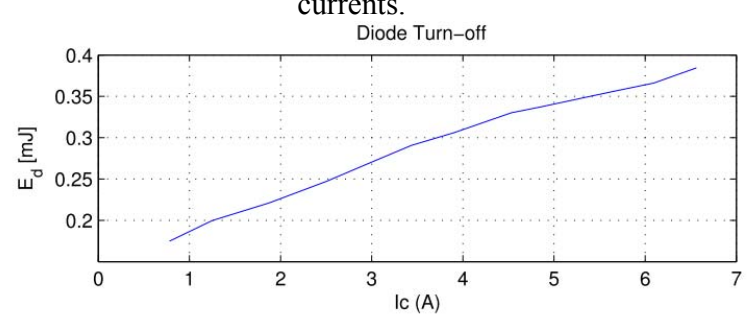

Fig. 19. Diode energy losses as a function of the collector currents.

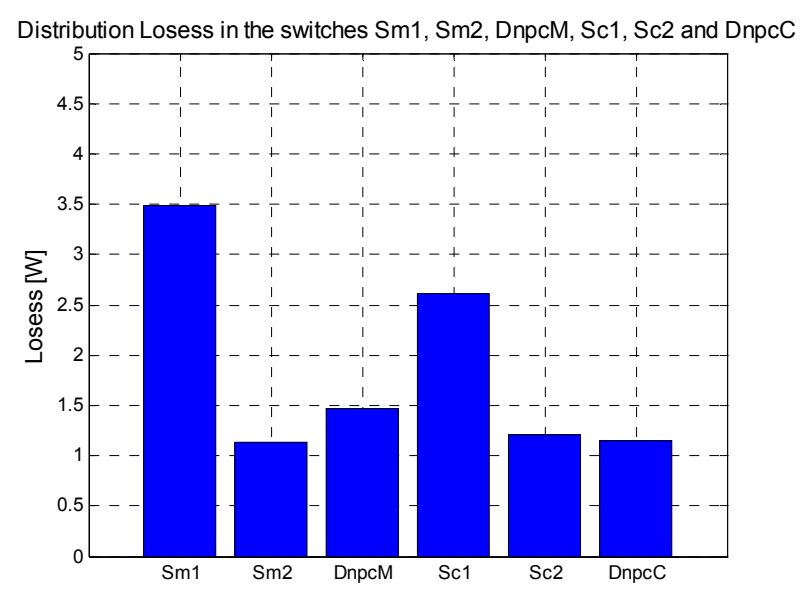

Fig. 20. Measured loss distribution for the main and clamping leg of the $5 \mathrm{~L}-\mathrm{MLC}^{2}$ converter.

computed as shows in Fig. 16 and Fig. 17. Finally, the dissipated energy losses as a function of the collector currents are depicted in Fig. 18 and Fig. 19 which are also in agreement with the datasheets.

The second experiment is evaluating the converter losses under the modulation strategy introduced in [9]. The power losses distribution of the converter was only measured for the upper part of the main and clamping leg due to the 
symmetrical losses observed in Fig. 5. In this setup, a 1.8 $\mathrm{kW}$ load with $\mathrm{PF}=1$ is used, and the switching frequency is set at $1.65 \mathrm{kHz}$. In order to emulate the grid connection, a $2.8 \mathrm{mH}$ inductive filter was used, and the modulation index was set to provide $400 \mathrm{~V}_{\text {rms }}$ output voltage. Fig. 20 shows the power distribution losses of the experimental setup. Note how the loss distribution is quite similar to the simulated one presented previously in Fig. 5, and the used model is appropriate in the system analysis.

\section{CONCLUSION}

It is found that the outer switches and clamping diodes are more loaded in this converter because of larger switching loss in both the main phase legs and the clamping leg of the $5 \mathrm{~L}-\mathrm{MLC}^{2}$ inverter. The switching loss in the main phase leg comes from the high voltage stress commutation (half of DC bus voltage), while the switching loss in the clamping leg comes from the high frequency switching within a fundamental cycle.

When complying with the active/reactive power operation range regulated by the German grid codes, the $5 \mathrm{~L}-\mathrm{MLC}^{2}$ inverter shows a good and consistent efficiency characteristic under different output active powers with both no reactive power operation and maximum underexcited reactive power boundary operation.

The experimental results show the loss distribution is in good agreement with the simulated ones when scaled down by the converter ratio.

\section{REFERENCES}

[1] S. Kouro, M. Malinowski, K. Gopakumar, J. Pou, L. G. Franquelo, B. Wu, J. Rodriguez, M. A. Perez, J. I. Leon, "Recent Advances and Industrial Applications of Multilevel Converters," IEEE Trans. on Power Electronics, vol. 57, no. 8, pp. 2553 - 2580, 2010.

[2] Ke Ma, Frede Blaabjerg, "The Impact of Power Switching Devices on the Thermal Performance of a 10 MW Wind Power NPC Converter," Energies, vol. 5, no. 7: 2559-2577.

[3] J. Rodríguez, L. G. Franquelo, S. Kouro, J. I. León, R. C. Portillo, M. A. M. Prats, and M. A. Pérez, "Multilevel Converters: An Enabling Technology for High-Power Applications", in Proc. IEEE, vol. 97, no. 11, pp. 1786-1817, Nov. 2009.

[4] F. Z. Peng, W. Qian, and D. Cao, "Recent Advances in Multilevel Converter/Inverter Topologies and Applications", in Proc. of IPEC' 2010, pp. 492-501, Jun. 2010.

[5] H. Akagi, "Classification, Terminology, and Application of the Modular Multilevel Cascade Converter (MMCC)", in Conf. Rec. IEEJ International Power Electronics Conf., Proc. of IPEC' 2010, pp. 508-515, Jun. 2010.

[6] M. H. Rashid, Power Electronics Handbook, Elsevier Inc., 3rd edition, Burlington, MA, USA, 2011, ch. 17.

[7] J. Rodriguez, S. Bernet, P. K. Steimer, and I. E. Lizama, "A Survey on Neutral Point Clamped Inverters", IEEE Trans. on Industrial Electronics, vol. 57, no.7, pp. 2219 - 2230, Jul. 2010.

[8] O. Apeldoorn, B. Ødegård, P. Steimer, S. Bernet, "A 16 MVA ANPC-PEBB with $6 \mathrm{kA}$ IGCTs," in Proc. of $40^{\text {th }}$ IEEE IAS Annual Meeting, vol. 2, pp. 818-824, 2005.
[9] J. Rodrigues, S. Bernet, J. O. Pontt and S. Kouro, "Multilevel voltage sources converter topology for industrial medium voltage drives," IEEE Trans. on Industrial Electronics, Vol.54, No. 6, pp. 2930-2945, 2007.

[10] P. Rodriguez, M. Bellar, R. Munoz-Aguilar, S. Busquets-Monge, F. Blaabjerg, "Multilevel-Clamped Multilevel Converters (MLC ${ }^{2}$ )," IEEE Trans. on Power Electronics, vol. 27, no. 3, pp. 1055-1060, 2011.

[11] P. Rodriguez, M. Bellar, R. Munoz-Aguilar, J. Rocabert, A. Luna, "Multilevel-clamped multilevel converters (MLC2)-an alternative approach for multilevel power conversion," in Proc. of IECON'2011, pp. 4433-4438, 2011.

[12] P. Rodriguez, R. Munoz-Aguilar, S. Busquets-Monge, M. Bellar, F Blaabjerg, "Virtual-vector-based space vector pulse width modulation of the DC-AC multilevel-clamped multilevel converter (MLC2)," in Proc. of ECCE'2011, pp. 170-176, Sep 2011.

[13] User manual of PLECS blockset version 3.1, March 2011.

[14] K. Ma, F. Blaabjerg, M. Liserre, "Thermal analysis of multilevel grid side converters for $10 \mathrm{MW}$ wind turbines under Low Voltage Ride Through," IEEE Trans. on Industry Applications, 2013.

[15] F. Blaabjerg, U. Jaeger, S. Munk-Nielsen and J. K. Pedersen, "Power Losses in PWM-VSI Inverter Using NPT or PT IGBT Devices," IEEE Trans. on Power Electronics, vol. 10, no. 3, pp. 358-367, May 1995.

[16] D. Graovac, M. Purschel, "IGBT Power Losses Calculation Using the Data-Sheet Parameters," Infineon Application Note, January, 2009.

[17] B. Backlund, R. Schnell, U. Schlapbach, R. Fischer, "Applying IGBTs," ABB Application Note 5SYA2053-01, May 2007.

[18] Semikron Simulation Software Semisel - Ver.4.1.2, 2013. (available: http://www.semikron.com/)

[19] W. Lixiang, J. McGuire,R.A. Lukaszewski, "Analysis of PWM Frequency Control to Improve the Lifetime of PWM Inverter," IEEE Trans. on Industry Applications, vol. 47, no. 2, pp. 922-929, 2011.

[20] C. Busca, R. Teodorescu, F. Blaabjerg, S. Munk-Nielsen, L. Helle, T. Abeyasekera, P. Rodriguez, "An overview of the reliability prediction related aspects of high power IGBTs in wind power applications," Microelectronics Reliability, Vol. 51, no. 9-11, pp. 1903-1907, 2011.

[21] I.F. Kovačević, U. Drofenik, J.W. Kolar, "New physical model for lifetime estimation of power modules," in Proc. IPEC'2010, pp 2106-2114, 2010.

[22] K. Ma, F. Blaabjerg, D. Xu, "Power Devices Loading in Multilevel Converters for 10 MW Wind Turbines," in Proc. of ISIE'2011, pp. 340-346, June 2011.

[23] M. Altin, O. Goksu, R. Teodorescu, P. Rodriguez, B. Bak-Jensen, L. Helle, "Overview of recent grid codes for wind power integration," in Proc. of OPTIM'2010, pp.1152-1160, 2010.

[24] E.ON-Netz - Grid Code. High and extra high voltage, April 2006.

[25] K. Ma, M. Liserre, F. Blaabjerg, "Reactive Power Influence on the Thermal Cycling of Multi-MW Wind Power Inverter," IEEE Trans. on Industry Applications, 2013.

[26] S. Tschirley and S. Bernet, "Automated testing of high power semiconductor devices," in Proc. of PELINCEC'2005, Warsaw, Poland, 2005.

[27] R. Alvarez, F. Filsecker, S. Bernet, "Characterization of a new 4.5 $\mathrm{kV}$ press pack SPT+ IGBT for medium voltage converters," in Proc. of ECCE'2009, pp.3954-3962, Sept. 2009. 